\title{
Empirical Investigation of Airline Service Quality and Passenger Satisfaction in India
}

\author{
S. SURESH, T. G. BALACHANDRAN and S. SENDILVELAN* \\ Dr. M.G.R. Educational and Research Institute, University, Chennai - 600095. India.
}

(Received on November 23, 2016)

\begin{abstract}
Service sector has become more relatively important as it has become a most essential part of any economy. One of the industries in this service sector is the Airlines industry. Being one of the modes of transport that propels the economic activity of a Nation, it has become essential to study the quality of service that should be made available to the users by this industry. So far the focus on airline service research has been to identify airline selection criteria and performance rankings. Of late the focus of research efforts has shifted to examine the issues inherent in various passenger segments. Prime objective of this study is to analyze the relationship between air passengers' class of service and their perception of service quality and also purpose of the trip, and satisfaction. This investigation indicates that majority of respondents perceived that responsiveness is most important, followed by tangibility, empathy, assurance and reliability. In contrary, consumer satisfaction level is more for tangibility followed by responsiveness, reliability, empathy and assurance.
\end{abstract}

Keywords: Air Passengers, Satisfaction, Service Quality, Statistical Approach

\section{Introduction}

With implementation of the Open Sky policy in 2016 in India that has enabled perfect competition; the competition in aviation sector has grown intense. Prime objective of this new policy is to improve airline service quality besides passengers' satisfaction. The Pros of deregulation has seen increase in air travel by the general public, more freedom to airline carriers, lower fares due to capacity availability, freedom to customers to select the air carrier etc. The Cons of deregulation are low profit margin for air carriers, increase in expenditure for improvement of safety and customer happiness, high labour attrition rate. It is clear that many passengers used fares as the main element in their selection of an airline [1].

Consequently, airlines used the value-of-service pricing strategy which means their fare structure is based on each customer segment's willingness to pay. They also included clauses like: non-transferable, non-refundable tickets, or minimum or maximum lengths of stay and payment in advance. The net result being quality of service that suffered as airlines continued to utilize low fares as the primary competitive weapon. The cut-throat competition in airlines' market has forced airline executives to pay due attention to customer service from the perspective of the general public.

\section{Purpose of the Study}

Research studies conducted earlier were on to identify airline selection criteria and performance rankings. Of late the focus of research efforts has now turned on to examine the issues inherent in various passenger segments. 
As these studies, did not provide adequate information on the interaction between air passenger satisfaction and the quality of services provided by the airline. Prime objective of this study is to analyze the relationship, in depth; in particular, to determine the relationship between:

- Air passengers' class of service and their perception of service quality

- Air passengers' purpose of the trip and their perception of service quality

- Air passengers' perceptions of service quality and satisfaction

\section{Research Methodology and Analysis Techniques}

Air passengers traveling via Chennai International Airport were taken as target sample. Chennai International Airport was selected for convenience, economy, and accessibility and also being an international facility as well as a major domestic hub in south India. A reasonable cross-section of airlines and all varieties of passenger classes were covered in this study. A total of 150 self-administered survey questionnaires were distributed randomly to passengers at the gates of four terminals viz. Kamaraj Domestic Terminal Departure I and II, Anna International Departure and Arrival Terminals. Out of this 118 usable responses were received which works out to $78.6 \%$.

\section{Expectations and Perceptions of Service Quality}

\subsection{Perceived Service}

Services usually require high consumer involvement in the production and consumption processes. Consumer may find a number of resources and activities to notice and evaluate. In this way, the quality of service is dependent on the expected service and perceived service [2, 3]. In this way, the quality of service is dependent on the expected service and perceived service. Introduction of new classification criteria for airports that focus on the passenger terminal facilities with four different kinds of comparisons: expected, deserved, ideal and minimum tolerable performance. The variables used to define the criteria include terminal size in terms of number of gates, passenger characteristics in terms of international/domestic passenger volumes and transfer passenger volume. Cluster analysis is used as the technique to identify similar airport groups using passenger volumes as multiple variables [4]. Johnston suggests that there are cultural norms people use to evaluate a product's performance. Satisfaction results from the degree to which perceived performance matches the norm [5].

\subsection{Unacceptable Quality}

This research indicates that satisfaction may not totally be dependent on whether a product performance meets or exceeds predicted performance. Standards, in the form of norms, may also have a role.

\subsection{Air Passenger Satisfaction}

In a competitive environment in the transportation sector, satisfying passengers will have a beneficial effect on a carrier's long-term survival [6]. The logistics literature is full of examples that show the importance of customer satisfaction [7]. The ability of a carrier to differentiate its services allows customer satisfaction to become a strategic weapon rather than an operational tool [8]. 


\subsection{Consumer Satisfaction and Dissatisfaction}

Airlines, as well as other businesses need to know how their services are meeting their clients' needs and wants so that they can enhance their own besides their clients wellbeing. Robert Johnston defines customer satisfaction in an equation form [9]. They believe customer satisfaction will not be based on a single factor, but rather will be the result of a combination of several factors consumers determine to be appropriate in the creation of satisfaction.

\subsection{Service Quality Measurement}

The airline industry has become competitive and aggressive in reducing expenditure. Little known are the programs used by some airlines to measure and standardize quality. Also, after deregulation, all airlines have started internet booking, Tele check-in, issuing e-Tickets and introducing apex fare to attract their customers.

\section{Summary}

Literature survey reveals that the most important factor affecting a firm's performance is the quality of its goods and services in relation to those of its competitors. Quality is especially difficult to define, describe, and measure in airline services. While quality and quality control measures are in existence for a long time for tangible goods, few such traditional measures exist for services. In essence, quality is determined by imprecise individual factors: perceptions, expectations and experience for consumers and providers. It includes airline service environment, service sector, service quality, expectations and perceptions of service quality, air passenger satisfaction and service quality measurement. Theoretical background to this study follows.

Air passengers traveling via Chennai International Airport (Anna International Terminal and Kamaraj Domestic Terminal) are the target sample. Chennai Airport was selected on the basis of convenience, economy, and accessibility. Although the literature indicates that many airport directors usually impose strict bans on questionnaire administration within their terminal areas, the administrative staffs at this particular air terminal were supportive of the research and provided the researcher access to passengers within the permissible area. Since Chennai is an international facility, as well as a major domestic hub, the researcher believes that sufficient cross-section of airlines and passengers could be covered. Thus, business and pleasure travellers, first, business and economy class travellers, domestic and international flights, and on-peak and off-peak flights were covered.

\section{Data Analysis}

\subsection{Introduction}

In accordance with the hypothesis set in the earlier chapter, the current study aims to analyze the relationship with the consumer expectation and satisfaction measures; in addition, this study also aims to correlate service quality with passenger diversity variables such as airline class and purpose of trip. To assume a satisfactory degree of reliability, passenger service quality of airline was measured with the SERVQUAL instrument comprising of 20 items and reduced to five item scale. Even though airline service quality and passenger diversity and satisfaction are crucial, little research had been performed to relate them. Results are presented in four sections; First section presents a 
profile of the sample respondents. Second section presents an overview of the data analysis including descriptive statistics of the responses. Third section presents the results of testing the hypotheses through the use of ANOVA and t-test. Fourth section summarizes the empirical results.

\subsection{Passenger Profile}

Among the 118 usable responses collected, 24 (20.3\%) were those flying first class, 2 (1.7\%) flying business class and 92 (78\%) those flying economy class; the same classified differently would mean 24 (20.3\%) flying for business reasons, and 54 (45.8\%) flying for pleasure or personal reasons. Data collected was used to unfold descriptive information about passengers which was related to their flying experience and demographics as shown in Table 1 . As per the survey, 22 (18.6\%) passengers flew on domestic flights and 58 (49.2\%) flew on international flights and 38 (32.2\%) of the total respondents travelled both domestic and international flights. Based on age classification, the sample comprises of 4 (3.4\%) under 25 years, 54 (45.8\%) between 26 and 40 years, 54 (45.8\%) between 41 and 60 years, and $6(5.1 \%)$ respondents above 60 years.

Passenger profile reveals that vast majority were flying economy class followed by business class. When it comes to the purpose of travel, pleasure/personal reasons dominates. They flew major air carriers for both domestic and international travels. They were from all age groups. They were from both genders, well-educated and fairly high income. The SPSS (Statistical Package for Social Sciences) was used to analyze the data. Reliability of the measures used in the survey was very strong. Values for coefficient alpha are greater than 0.85 which was well above the 0.60 minimum values suggested by Huysamen, considered necessary for exploratory research. Hypotheses testing the passenger diversity effect on airline service quality variables were carried out and results for the above hypothesis testing were presented [10].

Table 1: Respondents Profile

\begin{tabular}{|l|c|c|}
\hline & Frequency, $N=118$ & Percentage, 100 \\
\hline Age: & & \\
$<25$ & 4 & 3.4 \\
$26-40$ & 54 & 45.8 \\
$41-60$ & 54 & 45.8 \\
$>60$ & 6 & 5.1 \\
\hline Gender: & & \\
Male & 112 & 5.1 \\
Female & & 94.1 \\
\hline Purpose of & 24 & \\
Trip: & 40 & 20.3 \\
Business & 54 & 33.9 \\
Personal & & 45.8 \\
Pleasure & & \\
\hline Class traveled: & 24 & 20.3 \\
First class & 2 & 1.7 \\
Business & 92 & 78.0 \\
Economy & & \\
\hline Type of Travel: & 58 & 49.2 \\
International & 22 & 18.6 \\
Domestic & 38 & 32.2 \\
Combined & & \\
\hline
\end{tabular}


Data analysis was carried out via two sections, First section deals with consumer expectations with their corresponding achievement levels in total. Further, paired t-test was applied to check whether any significant difference exists between the expectation and achievement levels. Subsequent to this analysis next level of analysis was done to check differences if any among the different groups by applying different demographic, and psychographic variables. This analysis covers consumer expectations and achievements based on gender, type of travel, class of travel and age. Since the Gender has two groups, t-test was done. Other three variables have more than two variables and hence, ANOVA was done. Questionnaire includes 20 questions to study the consumer expectations and satisfaction levels based on the aviation industry in India at Chennai international airport. These 20 questions were grouped into five study variables viz., Reliability, Assurance, Empathy, Tangibility and Responsiveness as identified by Parusuraman and others in their SERVEQAL model [11]. Data collected were transformed into these five variables. Descriptive statistics for these five variables are provided in Table 2.

Table 2: Descriptive Statistics on Study Variables

\begin{tabular}{|l|c|c|c|c|}
\hline Variable & Mean & SD & t-value & $\begin{array}{c}\text { Significance } \\
\text { value }\end{array}$ \\
\hline Reliability: & & & & \\
$\begin{array}{l}\text { Expectations } \\
\text { Satisfaction }\end{array}$ & 4.0825 & 0.7755 & & \\
\hline Assurance: & 3.8347 & 0.7934 & 3.486 & 0.001 \\
Expectations & 4.0593 & 0.78764 & & \\
Satisfaction & 3.7331 & 0.75087 & 4.381 & 0.000 \\
\hline Empathy: & 4.0847 & 0.79476 & & \\
Expectations & 3.7881 & 0.83566 & 4.319 & 0.000 \\
Satisfaction & 4.1059 & 0.80091 & & \\
\hline Tangibility: & & & & \\
Expectations & 3.9449 & 0.68884 & 2.385 & 0.019 \\
Satisfaction & 4.1102 & 0.85269 & & \\
\hline Responsiveness: & 3.8475 & 0.82950 & 3.465 & 0.001 \\
Expectations & Satisfaction & & &
\end{tabular}

From the above table it is clear that the consumer expectations on Responsiveness are considered as the most important variable, followed by Tangibility, Empathy, Assurance and Reliability. In contrary, consumer satisfaction level is high for Tangibility followed by Responsiveness, Reliability, Empathy and Assurance [12]. Standard deviation for expectations and also satisfaction for all the variables are more or less the same within the range of 0.68 to 0.85 . After due consideration for the mean and the standard deviation (SD), next level of analysis was carried out using paired t-test to test the significance levels. This analysis indicates that for all the five variables there is a significant difference between expectations and satisfaction; consumer expectations are higher in comparison to existing service facilities. This needs a close scrutiny by airline service providers. 
Considering the importance based on study results, for Assurance level the difference is more (t-value 4.381) followed by Empathy (t-value 4.319), Reliability (t-value 3.486), Responsiveness (t-value 3.465) and Tangibility (t-value 2.385). These results throw some light on consumer priorities and achievements. Airline service providers can concentrate on these priorities in the order of preference.

Second section of analysis was carried out to check the group differences, if any, among the different categories of passengers based on different demographic and psychographic variables. These group differences can provide more detailed results and in depth knowledge on consumer preferences. These analyses were carried out in four sub sections viz., based on Gender, Age, Type of travel and Purpose of travel (refer Table 3).

Table 3: Expectancy and Achievement based on Gender

\begin{tabular}{|l|c|c|c|c|}
\hline Variable & \multicolumn{2}{|c|}{ Mean Scores } & & \\
\hline & Male & Female & t value & Significance \\
\hline Reliability: & & & & \\
Expectations & 4.1071 & 3.5833 & 1.623 & 0.107 \\
Satisfaction & 3.8482 & 3.5833 & 0.795 & 0.428 \\
\hline Assurance: & & & & \\
Expectations & 4.0714 & 3.8333 & 0.720 & 0.473 \\
Satisfaction & 3.7277 & 3.8333 & 0.335 & 0.739 \\
\hline Tangibility: & & & & \\
Expectations & 4.1027 & 4.1667 & 0.190 & 0.850 \\
Satisfaction & 3.9241 & 4.3333 & 1.424 & 0.157 \\
& & & & \\
\hline Responsiveness: & & & & \\
Expectations & 4.1473 & 3.4167 & 2.074 & 0.040 \\
Satisfaction & 3.8616 & 3.5833 & 0.799 & 0.426 \\
\hline Empathy: & & & & \\
Expectations & 4.0938 & 3.9167 & 0.530 & 0.597 \\
Satisfaction & 3.7991 & 3.5833 & 0.615 & 0.540 \\
\hline
\end{tabular}

Data analysis reveals that expectancy level of male passengers for all the five variables are more than 4.000 points and this range is from 4.0714 to 4.1473 . Top most priority was for Responsiveness and least priority was for Empathy. It was surprising to note that the satisfaction levels for all the five variables are also in the same priority order that is Responsiveness, Reliability, Tangible, Empathy and Assurance. This proves that service providers recognize the importance of service quality for men and provides it as per their expectations. For women top priority is given to Tangibility. Expectation for women was below 4.00 points for other four variables; hence satisfaction levels are as expected for women. Ultimate conclusion was male passengers' expectations are to be viewed seriously. Finally, when data analysis was carried out using ANOVA to check the difference between men and women on five variables for expectancy and satisfaction levels, it was clear that no significant difference exists between these two categories for all the five variables and also expectancy and satisfaction levels excepting expectance on Responsiveness differs significantly between men and women. In the forthcoming Table 4 details on comparison of expectancy and satisfaction levels for five variables based on the Age category of passengers has been made. 
Table 4: Expectancy and Achievement based on Age Group of Travelers

\begin{tabular}{|l|c|c|c|c|c|c|}
\hline \multirow{2}{*}{$\begin{array}{l}\text { Variable } \\
\text { Age }\end{array}$} & \multicolumn{3}{|c|}{ Mean Scores } & & & \\
\cline { 2 - 7 } & $\begin{array}{c}<5 \\
\mathrm{~N}=4\end{array}$ & $\begin{array}{c}26-40 \\
\mathrm{~N}=54\end{array}$ & $\begin{array}{c}41-60 \\
\mathrm{~N}=54\end{array}$ & $\begin{array}{c}>60 \\
\mathrm{~N}=6\end{array}$ & $\begin{array}{c}\text { ANOVA } \\
\text { F value }\end{array}$ & Significance \\
\hline Reliability: & & & & & & \\
Expectations & 4.875 & 3.9167 & 4.1944 & 4.000 & 2.729 & 0.047 \\
Satisfaction & 2.000 & 3.7593 & 4.0093 & 4.1667 & 10.612 & 0.000 \\
\hline Assurance: & & & & & & \\
Expectations & 5.000 & 3.8611 & 4.1944 & 4.000 & 3.844 & 0.012 \\
Satisfaction & 2.000 & 3.6574 & 3.8704 & 4.3333 & 11.674 & 0.0000 \\
\hline Tangibility: & & & & & & \\
Expectations & 5.000 & 3.9815 & 4.1852 & 3.9167 & 2.474 & 0.065 \\
Satisfaction & 2.875 & 3.8241 & 4.1019 & 4.333 & 6.029 & 0.001 \\
\hline Responsiven & & & & & & \\
ess: & 4.875 & 3.9259 & 4.2222 & 4.2500 & 2.357 & 0.075 \\
Expectations & 2.375 & 3.7685 & 3.9815 & 4.3333 & 6.266 & 0.001 \\
Satisfaction & & & & & & \\
\hline Empathy: & & & & & & \\
Expectations & 5.000 & 3.8611 & 4.2593 & 3.9167 & 4.526 & 0.005 \\
Satisfaction & 2.875 & 3.7130 & 3.9167 & 3.9167 & 2.284 & 0.083 \\
\hline
\end{tabular}

This data analysis reveals that expectancy level for the first group namely, below 25 years is generally higher. This may be due to better information about the service facilities available elsewhere due to their wide travel experience. This conclusion was drawn because for top most categories namely, above 60 years old, satisfaction level was higher than expectancy levels. For middle order categories, expectancy levels are above satisfaction levels but in contrary, difference between expectancy and satisfaction levels are insignificant. ANOVA results reveal that for almost all the five variables and for both expectancy and satisfaction levels there was a significant difference for all the four groups of passengers. This is a strong indication that Expectancy and Satisfaction levels differ based on Age category. Airline service providers should note this difference, and should differentiate service for matching the expectations of various age groups of passengers. Subsequent analysis was done based on type of travel. This may provide critical information on type of service required by different categories of passengers (refer Table 5).

Table 5: Expectancy and Achievement based on Type of Travel

\begin{tabular}{|l|c|c|c|c|c|}
\hline Variable & \multicolumn{3}{|c|}{ Mean Scores } & & \\
\hline Purpose of Travel & $\begin{array}{c}\text { Business } \\
\mathrm{N}=24\end{array}$ & $\begin{array}{c}\text { Personal } \\
\mathrm{N}=40\end{array}$ & $\begin{array}{c}\text { Pleasure } \\
\mathrm{N}=54\end{array}$ & $\begin{array}{c}\text { ANOVA } \\
\text { F value }\end{array}$ & Significance \\
\hline Reliability: & & & & & \\
Expectations & 3.9167 & 4.0250 & 4.1944 & 1.226 & 0.297 \\
Satisfaction & 3.8333 & 3.9375 & 3.7593 & 0.576 & 0.569 \\
\hline Assurance: & & & & & \\
Expectations & 3.8542 & 4.0875 & 4.1296 & 1.056 & 0.351 \\
Satisfaction & 3.7083 & 3.9625 & 3.5741 & 3.207 & 0.044 \\
\hline
\end{tabular}




\begin{tabular}{|l|l|l|l|l|l|}
\hline Tangibility: & & & & & \\
Expectations & 3.6667 & 4.2000 & 4.2315 & 4.848 & 0.010 \\
Satisfaction & 3.7917 & 4.0625 & 3.9259 & 1.201 & 0.305 \\
\hline Responsiveness: & & & & & \\
Expectations & 4.0208 & 4.0750 & 4.1759 & 0.323 & 0.725 \\
Satisfaction & 3.8333 & 3.9025 & 3.7685 & 0.629 & 0.535 \\
\hline Empathy: & & & & & \\
Expectations & 3.9375 & 4.0625 & 4.1667 & 0.711 & 0.493 \\
Satisfaction & 3.6667 & 3.9750 & 3.7037 & 1.543 & 0.218 \\
\hline
\end{tabular}

This analysis reveals that expectancy levels and satisfaction levels of different type of travellers are almost the same. Expectancy level was about 4.00 and satisfaction level was about 3.700. Little variation exists between expectancy and satisfaction levels. ANOVA results also confirm that there was not much difference for various categories of passengers based on their purpose of travel. For all five variables the significance levels are above 0.05 for expectancy and satisfaction. Hence the conclusion is that airline service providers match the expectations of different categories of travellers based on the purpose of travel. This final analysis deals with the mean score of five variables based on the class of travel of the air passengers. This is likely to yield vital information about the expectations of various classes of passengers and requisite management strategies (refer Table 6).

Table 6: Expectancy and Achievement based on Class of Travel

\begin{tabular}{|l|c|c|c|c|c|}
\hline Variable & \multicolumn{3}{|c|}{ Mean Scores } & \\
\hline Class of Travel & $\begin{array}{c}\text { Economy } \\
\mathrm{N}=92\end{array}$ & $\begin{array}{c}\text { Business } \\
\text { class } \\
\mathrm{N}=2\end{array}$ & $\begin{array}{c}\text { First class } \\
\mathrm{N}=24\end{array}$ & $\begin{array}{c}\text { ANOVA } \\
\text { F value }\end{array}$ & Significance \\
\hline Reliability: & 4.0761 & 4.2500 & 4.0833 & 0.49 & 0.953 \\
Expectations & 3.8533 & 4.2500 & 3.7292 & 0.507 & 0.604 \\
Satisfaction & & & & & \\
\hline Assurance: & 4.0543 & 4.000 & 4.0833 & 0.018 & 0.982 \\
Expectations & 3.7337 & 4.000 & 3.7083 & 0.137 & 0.872 \\
Satisfaction & & & & & \\
\hline Tangibility: & 4.0924 & 4.5000 & 4.1250 & 0.259 & 0.772 \\
Expectations & 3.9457 & 4.5000 & 3.8958 & 0.707 & 0.495 \\
Satisfaction & & & & & \\
\hline Responsiveness: & 4.1250 & 4.2500 & 4.0417 & 0.116 & 0.890 \\
Expectations & 3.8696 & 4.2500 & 3.7292 & 0.508 & 0.603 \\
Satisfaction & & & & & \\
\hline Empathy: & 4.0924 & 4.0000 & 4.0625 & 0.025 & 0.976 \\
Expectations & 3.8424 & 4.0000 & 3.5625 & 1.136 & 0.325 \\
\hline Satisfaction &
\end{tabular}

Data analysis reveals that Business class travellers are the most satisfied category among these three groups. For them, expectancy and satisfaction levels are almost the same. For the other two categories, there is a significant difference between their expectation and satisfaction levels. Even within these two categories, Economy class of 
passengers' expectation level is more when compared to First class passengers. Economy class is the major chunk in numbers; hence management should consider providing better service facilities to this class of passengers. For the other two categories also they should maintain the service facilities as per their expectation. ANOVA results prove that there is not much difference for the three classes of passengers. For all the five variables, significance levels are above 0.05 for expectations and satisfaction.

\subsection{Research Findings}

Research findings are presented according to the hypotheses tested. This investigation indicates that majority of respondents perceived that Responsiveness is the most important, followed by Tangibility, Empathy, Assurance and Reliability. In contrary, consumer satisfaction level is more for Tangibility followed by Responsiveness, Reliability, Empathy and Assurance. It is surprising to note that priority order for satisfaction levels for all the five variables are also the same, viz., Responsiveness, Reliability, Tangibility, Empathy and Assurance. Results reveal that service providers are recognizing the importance of service quality as per the priorities of male passengers and providing the same as per their expectations. For female passengers higher priority is to be given to Tangibility than the other four variables since the expectancy scores are lower than 4.0.

\section{Conclusion}

Results of this investigation are of practical relevance to both the airline industry and logistics researchers concerned with air travellers' behaviour. They provide an empirical basis for evaluation of airline services and indicate that some current service offerings designed for leisure traffic may be attractive to business travellers. Traditional means of segregating air travel market into business and pleasurelpersonal fliers appears to be invalid. There is no appreciable difference between business class travellers and coach class travellers in their evaluation of airline service quality and their satisfaction from the services provided by the airlines. The airlines may need to examine differentiating business class services to enhance the effectiveness.

\section{References}

[1]. Martín, J. C., C. Román, and R. Espino. Evaluating Frequent Flyer Programs from the Air Passengers' Perspective. Journal of Air Transport Management, 2011;17:364-368.

[2]. Gronroos, C. Adopting a Service Logic for Marketing. Marketing Theory, 2006;6:317333.

[3]. Zaibaf, M., F. Taherikia, and M. Fakharian. Effect of Perceived Service Quality on Customer Satisfaction in Hospitality Industry: Gronroos' Service Quality Model Development. Journal of Hospitality Marketing \& Management, 2013;22:490-504.

[4]. Adikariwattage, V., A.G. de Barros, S.C. Wirasinghe, and J. Ruwanpura. Airport Classification Criteria Based on Passenger Characteristics and Terminal Size. Journal of Air Transport Management, 2012;24:36-41.

[5]. Johnston, R. Service Operations Management. Service Management, 2008; 1016: 263269.

[6]. Jou. R.C., S.H. Lam, D.A. Hensher, C.C. Chen, and C.W. Kuo. The Effect of Service Quality and Price on International Airline Competition. Transportation Research Part E: Logistics and Transportation Review, 2008;44:580-592.

[7]. Flint, D.J., E. Larsson, B. Gammelgaard, and J.T. Mentzer. Logistics Innovation: $a$ 
Customer Value-Oriented Social Process. Journal of Business Logistics, 2005;26:113147.

[8]. Gustafsson, A., M.D. Johnson, and I. Roos. The Effects of Customer Satisfaction, Relationship Commitment Dimensions, and Triggers on Customer Retention. Journal of Marketing, 2005;69:210-218.

[9]. Johnston, R. The Determinants of Service Quality - Satisfiers and Dissatisfiers. International Journal of Service Industry Management, 1995;6:53-71.

[10]. Huysamen, G.K. Coefficient Alpha: Unnecessarily Ambiguous; Unduly Ubiquitous. Journal of Industrial Psychology, 2006;32:34-40.

[11]. Parasuraman, A., L. Berry, A. Parasuraman, and L. Berry. Refinement and Reassessment of the Servqual Scale. Journal of Retailing, 2004:420-450.

[12]. Scott, W., M. Erkoc, and J.Sharit. Assessment of Airport Air Side Performability from the Perspective of the Consumer. International Journal of Performability Engineering, 2011; 7(2): 121-136.

S. Suresh is a professor in the Department of Mechanical Engineering, Dr. M. G. R. Educational and Research Institute, University. He has completed his B.E (Honors) M.S. in US. He has 30 years' experience in Teaching and Consultant work.

T. G. Balachandran, is a graduate in commerce, after graduation he joined Loyola College as a Faculty in commerce. In 1973, he joined Southern India Petrochemicals Limited and held several senior positions covering various financial disciplines in SPIC and its group companies. During the year 1996, he took over as operations In-charge of Ind-Ital Chemicals Limited and reached the position of director and chief executive officer. He was with Sri Venkateswara College of Engineering holding the position of secretary and Registrar. He is presently Director Admin, at Dr. M. G. R. Educational and Research Institute, University.

S. Sendilvelan obtained his AMIE (Mechanical Engineering) degree from IEI. He also obtained his M.E. in Thermal Power Engineering from Annamalai University and he secured Gold Medal from Pondicherry University for his M. Tech. (CAD) Course. He acquired his Ph.D. from Anna University, Chennai for his research work in the area of IC Engine Emission Control. He has guided 9 candidates for their research leading to $\mathrm{Ph}$. D degree. He has published more than 104 articles in National and International Journals. He has 164 citations in the International Journals including Elsevier, Vehicle EngineGermany and IMechE proceedings. He was a member of several technical committees on National and International conferences. He is the member of several Indian and International professional bodies. He is currently working as Professor in Mechanical Engineering Department, Dr. M.G.R. Educational and Research Institute, University, Chennai. 